\title{
More trials are cut short, but not the debate over their trajectory
}

In November of last year, Jeanne Marrazzo received some bad news. Marrazzo had helped design the VOICE study, a 5,000-person clinical trial testing three HIV-prevention interventions: a vaginal gel containing the drug tenofovir, a tenofovir pill and a combination pill known as Truvada that also contains emtricitabine. At a routine meeting with an independent review board to discuss the trial's progress, Marrazzo was unexpectedly told to discontinue the arm of the study testing the gel because that particular intervention didn't work at all. The oral tenofovir had been previously discontinued for the same reasons, leaving just the Truvada arm.

Since that day in November, Marazzo has seen the data and says she has made her peace with the decision to end the trial, which stands for Vaginal and Oral Interventions to Control the Epidemic. But the early end of other trials in the preceding months, such as one testing niacin to prevent heart attacks, have not sat as well with other researchers.

One thing that most agree on is that there seems to be no end to the trend of truncated trials: a 2008 paper cited a $50 \%$ increase in numbers of stopped cancer drug trials since 2006, compared to the total number of halted trials from 1998 to 2007 (Ann. Oncol. 19, $1347-1353,2008)$. And the functions of the independent panels of experts that monitor interim study results, known as data and safety monitoring boards (DSMBs), have prompted recent objections: a review published last June argued that DSMBs, which have the power to stop trials, should consider factors beyond pure statistics-such as previous scientific knowledge of the treatment and impact of the halt-when recommending trial closure (Eur. J. Cancer 47, 2381-2386, 2011).

The authors of the paper say that regardless of whether DSMBs choose to halt a trial due to the overwhelming benefit or futility of an intervention, they sometimes rob the scientific community of valuable clinical data. As a result, "you will never see the big picture," says review author Som Mukherjee at McMaster University, in Ontario, Canada.

The closely watched AIM-HIGH trial, which tested the benefit of niacin in reducing heart attacks, was stopped last April because the drug seemed ineffective. It also showed a slightly increased risk of stroke at the time of its analysis. Controversially, the final results, published in November, found no increase in risk of stroke-although they also failed to demonstrate a clinical benefit (N. Engl. J. Med. 365, 2255-2267, 2011).

Experts such as cardiologist Steve Nissen from the Cleveland Clinic in Ohio voiced their opposition to the halting of the AIMHIGH trial. In a story published on theheart. org, Nissen was quoted as saying that the US National Institutes of Health (NIH) had made a panicked decision to end the trial based on a weak statistical signal of strokes. He added that the NIH had squandered an opportunity to learn more about the effects of niacin.

But David Gordon, executive secretary of the trial's DSMB, insists futility of the intervention, and not stroke risk, was the reason for stopping the trial. Nissen did not respond to requests for comment for this article.

To ensure the right decision is made, more transparency is needed in DSMBs' deliberative process, according to Mukherjee, because, ultimately, he says, everyone has the same goal: "We all want to get drugs out to our patients as quickly as possible."

Madhumita Venkataramanan

\section{EU court gets tough on patent extensions for combo products}

Time is money, and that is what makes the lag between the filing of a patent application for a drug and the date it hits the market so painful for companies to endure. To make up for the wait, in 1992 the EU introduced 'supplementary patent certificates' (SPCs), which can grant up to five years of additional market exclusivity after the underlying patent of a medicine expires. Now, after two recent rulings in the EU, experts warn that drugmakers should plan more carefully when seeking SPCs for combination drugs, which can be complicated because these products often contain ingredients beyond those covered by a company's patents.

When it comes to combination drugs, SPC approval guidelines have varied from country to country in the EU—something that companies have not been too happy about. The law creating the SPC framework "was a very short piece of legislature that caused a huge number of problems," says Robert Stephen, head of patent prosecution at the London law firm Olswang. But on 24 November, the Court Justice of the European Union (CJEU) handed down decisions on two cases, clarifying how countries across the EU should apply SPCs to combination products.

In one of the cases brought before the high court, Dutch drugmaker Medeva BV, now a subsidiary of the UK-based pharmaceutical company Celltech Pharma Europe, was seeking an SPC to cover the expanded use of its patented ingredients in the whooping cough vaccine to other types of vaccines that included additional unpatented components. But, ultimately, the gavel struck hard: the judges made it clear that an SPC can cover only those drugs listed in the basic patent and nothing more. "The idea that there is any way around this is, I think, wishful thinking," says Jonathan Radcliffe, an intellectual property lawyer at Mayer Brown in London.

"What the court is looking for is that the combination-if it's going to be a truly different product-needs to represent a different innovation from the single active ingredients" covered in their patent, says Mike Snodin, a pharmaceutical lawyer at Potter Clarkson in the UK. "I imagine that there are a number of nervous companies out there."

On the flipside, in the second decision on 24 November the EU high court said SPCs could be granted for drugs that involve only a subset of active ingredients listed in the underlying patent. That case involved several US universities-including Georgetown University in Washington, DC_-seeking SPCs for a subset of elements of the human papilloma virus vaccine originally listed in their patents.

For patent lawyers, the immediate effects of the decisionsparticularly the Medeva case-is clear: "Anyone who is filing patents in Europe on products that might be used in combination with other products will have to be very careful in the future in the way they write their patent claims," says Duncan Curley, head of patents at Innovate Legal in London. Patent writers, he explains, will be forced to gaze into their crystal balls to predict every potential combination to ensure the patent will cover it later.

Hannah Waters 